\title{
Perceptions of behaviours in stranger rape cases: A sequence analysis approach.
}

\author{
Ellis, H. E. ${ }^{1}$, Clarke, D. D. ${ }^{2}$, Keatley, D. A. ${ }^{1 *}$
}

${ }^{1}$ Researchers in Behaviour Sequence Analysis (ReBSA), School of Psychology, University of Lincoln, Lincoln, LN6 7TS

${ }^{2}$ Researchers in Behaviour Sequence Analysis (ReBSA), Emeritus Professor, School of Psychology, University of Nottingham, Nottingham, NG7 2RD

Correspondence Author: David Keatley, Researchers in Behaviour Sequence Analysis (ReBSA), School of Psychology, University of Lincoln, Lincoln, LN6 7TS, Email: DKeatley@lincoln.ac.uk 


\begin{abstract}
Psychological research into perceptions of sexual attacks, rape myths and scripts usually involves questionnaires or qualitative reports. A new method for investigating the perceived dynamic sequence of behaviours between victim and attacker could help to outline common perceptions. The current study uses a Behaviour Sequence Analysis approach to investigate females' perceptions of the interaction between a female victim and unknown, male attacker. A sample of females were asked to report their perceptions of the interaction between a female and stranger at night, leading-up to a rape attack. Results indicated that females did not perceive weapons or excessive force to be likely behaviours. Also, females responded that most attackers would begin by first attempting to engage a female in conversation. An important contribution of the current research is to show temporal associations between behaviours. In addition, the current research highlights the strength of sequence analysis for understanding perceptions of dynamic patterns of violent behaviours.
\end{abstract}

Keywords: Rape; sexual assault; behaviour sequence analysis; rape myths; rape scripts 
Perceptions of behaviours in stranger rape cases: A sequence analysis approach.

\section{Introduction}

The number of reported rapes has risen in England and Wales over the last 20 years (Kelly, Lovett, \& Regan, 2005). Approximately 85,000 women are raped in England and Wales every year (Office for National Statistics, 2015). Nevertheless rape is generally thought to be an underreported crime (Home Office \& Ministry of Justice, 2013). Rape is legally defined as intentional penile penetration of the vagina, anus, or mouth, where the victim does not consent, or the perpetrator does not reasonably believe that the victim consents (Sexual Offences Act 2003 s.1.) Rape can have a shattering effect on a person’s wellbeing both psychologically and physically (Koss, Figueredo, \& Prince, 2002).

Research examining sexual assault and rape typically uses a number of approaches (Fossi, Clarke, \& Lawrence, 2005). Some previous research, focused on victim characteristics, outlines how victims respond or react to offenders in a rape cases (Carter, Prentky, \& Burgess, 1995; Scully, 1990). Other previous research has also focused on offender typologies or profiles (Canter \& Heritage, 1989). In this, characteristics of the assailant are investigated to understand the aetiology of individuals who commit sexual violence and rape (Canter \& Kirby, 1995). Victims’ experiences and meanings related to the traumatic experience are also incorporated into research, with the aim of developing support services for psychological and physiological consequences following sexual assaults. These approaches have given great insight into the field of sexual assault and rape cases. However, while many studies focus on either qualitative or quantitative methods; a method that combines the data-richness of the former with the statistical generalisations of the latter could prove beneficial to research. Therefore, an alternative approach, Behaviour Sequence Analysis (BSA), which transforms qualitative reports into quantitative outputs to understand 
rape cases will be outlined in the current paper. BSA allows the complex patterns of perceived behaviours leading up to rape attacks to be systematically and statistically analysed to show most common pathways. In the current study, this will allow clearer comprehension of sequences that females perceived as being most likely to end in a sexual assault. The current study, therefore, is based on females' perceptions relating to stranger rape attacks, as these attacks are diverse in their initiation and behaviours.

Understanding how victims behave in sexual assaults and rape cases has been previously researched in relation to rape myths or scripts (Kahn, Mathie, \& Torgler, 1994; Ryan, 2011; Ullman, 2007). Rape myths are a false belief about rape (Ullman, 2007); for example, claiming rape will only occur down a dark alleyway, by a stranger (Gölge, Yavuz, Müderrisoglu, \& Yavuz, 2003), or claiming the victim should physically resist their attacker (Kassing \& Prieto, 2003). Rape myths and scripts, therefore, offer some insights into individuals' perceptions of rape cases; however, the current research presents a method that allows the systematic analyses of qualitative accounts into quantitative data.

Exactly what a person should do when they are challenged by an offender is debated (Lawrence, Fossi, \& Clarke, 2010). Research shows that victims who respond with physical or verbal strategies, such as shouting for help, are less likely to be attacked (LevineMacCombie \& Koss, 1986). Woodhams, Hollin, Bull, and Cooke (2012) suggest that in actual rape cases not all victims will engage in physical forms of resistance, but instead report a range of different types of behaviours. However, research has also shown that if victims fought back, this may lead to an increase in perpetrator violence and could lead to serious injury or death (Lees, 1997). In some cases, verbal and physical resistance increases sexual excitement of dominant, aggressive, and highly assaultive rapists (Carter et al., 1988, Sleath \& Woodhams, 2014). Additionally, Ullman (2007) suggested that women should resist rape both verbally and physically and should be taught effective strategies, such as self-defence in 
education. However, the attacker's behaviour will influence the victim's behaviour, or vice versa. The perceptions of how a female will behave when approached by an attacker and how the interactions between victim and attacker occur will be explored in the current paper. This will show if current perceptions correlate with previous research (Levine-MacCombie \& Koss, 1986) and outline some of the complexity in behaviour interactions. Indeed, understanding females' perceptions of the sequence of stranger rape attacks may provide insight into potential areas of increased risk (i.e., if females are unaware of a particular sequence of events that investigations and police files have suggested occur). Understanding perceptions of rape attacks could be used to develop awareness raising initiatives to reeducate or clarify misconceptions about behaviour patterns.

\subsection{Behaviour Sequence Analysis (BSA)}

The current research focuses on females' perceptions of interactions between a female victim and a male stranger leading up to a rape attack, which develops previous literature in the area (Fossi et al., 2005; Lawrence et al., 2010). One way to analyse such behaviours, would be to examine the frequency of independently occurring behaviours, based on selfreports from victims, statements from offenders, and police reports. However, these methods may contain inaccuracies, such as deception or omissions (Alison, 2001; Page, 2008). Furthermore, frequencies alone do not offer causal information about the progression of behaviours over time. Jones and Gerard (1967) suggested a person’s present behaviour is not only affected by their own previous behaviour, but also other people’s behaviours.

Understanding the pattern of interactions will form a set of rules, or grammar, allowing prediction of likely responses of an individual to a range of different behaviours (Fossi et al., 2005). 
BSA takes individual cases and produces a chain of events or sequences that show typical patterns of behaviour in a given situation, such as the sequence of events leading up to a rape offence. In the current study the sequence analysis will show the common perceived pathways, between a female leaving a bar at night and a rape attack taking place on her journey home. There is, obviously, a vast array of possibilities in which a stranger rape can occur; therefore, the current scenario was chosen to show the effectiveness of BSA as a method of reducing complexity in sequential chains. In the simplest form of BSA, also known as a lag-one sequence analysis, relationships between behaviour pairs are analysed (Ivanouw, 2007). For example, a list of behaviours such as: $a, b, c$, and $d$ (which relate to specific behaviours) are analysed to identify which antecedent behaviour causes subsequent outcomes to be more likely to occur (i.e., $A \rightarrow B, B \rightarrow C, C \rightarrow D$ etc.). Transitions between behaviours can then be plotted in a map, called a state transition diagram.

Behaviour Sequence Analysis (BSA) is a useful method for categorising behaviours or events and investigating the sequential pattern between them (Bakeman \& Quera, 2011; Fossi et al., 2005; Lawrence et al., 2010; Keatley, Barsky, \& Clarke, 2017; Marono et al., 2017a, 2017b; Taylor, Keatley, Clarke, 2017). BSA has been used in previous related research to examine behavioural patterns such as verbal strategies during bedroom rapes (Lawrence et al., 2010) and patterns of behaviours in sexual assaults (Fossi et al., 2005). This research outlined actual behaviours and strategies used by individuals, based on police reports of the incident. There are also several papers looking at semi-sequentual and crimelinkage analysis, which provide similar approaches to the current research (Balemba \& Beauregard, 2012; Woodhams, Hollin, \& Bull, 2008). However, the current research builds on this literature to understand females' perceptions of behaviours in a stranger rape case over longer sequences. Obviously, this is a vast area with almost limitless possibilities; 
therefore, to focus responses slightly, participants were informed that the female in question had just left a bar and was making her way home ${ }^{1}$.

\section{Method}

\subsection{Participants}

A sample of participants $(\mathrm{N}=124)$ were initially recruited via university participation systems. Of the 124 participants who completed the survey, 31 were removed due to incomplete or illegible data, leaving 93 females $\left(M_{\mathrm{age}}=25.16\right.$, SD $=12.85$; range $\left.=18-64\right)$ in the final sample. While all participants indicated some basic awareness of rape cases and assaults, no-one in the current sample claimed to have had personal experience. All participants were from a European (UK) background. Participants were awarded course credit for completion of the study. The Ethics Review Board at the University of Lincoln, UK, approved the current study, and all participants gave informed consent.

\subsection{Behaviour list}

Initially, an extensive literature search was conducted on case reports and research of rape cases and typical victim and offender behaviours. This gave an initial list of behaviours that occurred during real reported cases. Searches of academic literature, using specific key words, such as 'rape', 'rapist', 'victim', 'offender', 'attacker', and 'behaviours', identified numerous academic journals and articles about rape research. These journals provided behaviours, such as those identified in Lawrence et al. (2010), in rape offences. At the end of this stage of the research, a total of 52 mutually exclusive behaviours were put into a final list. However, to ensure an exhaustive list of behaviours, which is a prerequisite of sequence

\footnotetext{
${ }^{1}$ Although this adds a constraint to the generalisability of the data, it is necessary to have some kind of parameter on the situation to allow aggregation of data. The use of a bar also overlaps previous research that has established stranger rapes to be associated with bars/drinking establishments (Waterhouse, Reynolds, \& Egan, 2016).
} 
analysis research (Bakeman \& Quera, 2011), the final list given to participants also included space for participants to add any additional behaviours they thought had occurred. The list of 52 behaviours were piloted among a group of participants $(\mathrm{N}=15)$ with the focus being on adding any behaviours they thought relevant. Of the 15 participants, none indicated further behaviours that were likely to occur; therefore, the list was kept at 52. During the actual testing stage, 3 additional behaviours were added by separate participants. These were: “female pretends to use phone”, “Attacker looks at woman inappropriately”, “female is followed"2.

\subsection{Procedure}

The task was administrated online, via a questionnaire survey system. Participants were first given an example sequence analysis task, to ensure they understood the process and instructions. The example gave a completely unrelated scenario, followed by an explanation of how to complete the task. When participants fully understood the task, they were prompted to continue to the main task.

On the first screen of the main task, participants were presented with the list of possible behaviours, including the first behaviour 'female leaves bar' and the last behaviour 'attacker rapes female'. The participant was directed to read and familiarise themselves with the full list of behaviours, and select only the behaviours they thought occurred in one particular rape case. Participants were told not to make generalisations or pick 'most likely' behaviours; but, only the behaviours relevant for a single incident. Essentially, participants were meant to write a single story about one possible specific timeline of events. Participants were not meant to write in 'generalities' or 'most likely' events overall. For instance, they were asked not to include behaviours they thought occur in most cases, but were not actually

\footnotetext{
2 These additions happened late in the testing stage, and therefore were not added to the behaviour list for remaining participants. Future research, however, should include these behaviours.
} 
relevant to their timeline. Participants could also add behaviours to the list on this screen if they wanted. Participants were reminded that only behaviours selected would be brought forward to the sequencing stage of the study (though there was an option to return to this screen if they wanted to).

Once the participant had selected only the behaviours they wanted to include in their single rape case, they pressed continue and only those behaviours were brought forward. Participants were now directed to put the behaviours in the order in which they occurred. Behaviours could be used multiple times, if participants thought there was repetition of behaviours. This meant a logical progression of behaviours was established from the start to end points, in the rape case scenario. Participants were encouraged to use as many behaviours as they deemed necessary, and were not given time-specific constraints, either in completing the study or in how long the perceived attack lasted. On average, participants took 10 minutes to complete this task.

\section{Results}

\subsection{Pre-Analysis}

The data were initially screened to ensure all sequences were complete and coherent ${ }^{3}$. The next stage was to collate all of the proposed sequences from the 93 participants. The collated sequences were then entered into a statistical programme R (R Core Team, 2013) to calculate a lag-one sequence analysis. An example of a lag-one sequence (using the previous examples of $a, b, c$ and $d$ ) is: a-b, or c-a, or b-d etc. Essentially, a lag-one sequence, takes an antecedent behaviour, ('a') and a sequitur behaviour, ('b’) and analyses whether 'a' leads to ' $\mathrm{b}$ ' occurring more frequently than expected by chance. For lag-one sequence analysis, the $\mathrm{R}$

\footnotetext{
${ }^{3}$ No data in the final analysis had fewer than 6 behaviours selected, which indicated the final sample of participants were suitably invested in the study and completed it properly.
} 
programme analyses all possible behaviour pairs. The programme then positions all of those behaviours across the chains of sequences that each participant gave.

Lag-one sequence analysis was used over other approaches, such as lag-two, or higher order analysis, for several reasons. Firstly, the lag-one analysis mimics some aspects of research that has been conducted in the area of rape and sexual assault (such as crime script analysis, and crime-linkage analysis). More importantly, lag-one analysis allows researchers and investigators to see transitions between single behaviours (e.g., 'A' to 'B'). If a lag-two or higher order analysis is conducted (i.e., 'AB' to 'C') then in practical terms the researcher or investigator would need to wait and see the co-occurrence of 'AB' before being able to predict that 'C' will follow. Furthermore, this higher order approach typically leads to overfitting of sequences to the current dataset, which actually limits generalisability to other cases. Therefore, as lag-one analysis is more typically used in the literature (Keatley et al., 2017; Taylor et al., 2017), it was used in the current research.

\subsection{Sequence Analysis}

Before a sequence analysis occurs, frequencies of individual behaviours are calculated (see Table 1). This frequency analysis provides initial indication of which behaviours and events participants thought most likely to occur. The most frequently occurring behaviours were female resists $(n=86)$, female screams $(n=73)$, attacker covers female's mouth $(n=$ 73), attacker approaches from behind $(n=72)$, attacker pulls female to the ground $(n=72)$, and attacker grabs female's clothes $(n=72)$. This provides an initial account of most frequent behaviours, which can be compared to crime reports and statistics; however, the behaviour sequence analysis takes these individual behaviours and indicates the transitions between them. 
The main stage of sequence analysis is to find all behaviour pairs that occur statistically above the level of chance. To ascertain this, the programme in $\mathrm{R}$ ran a Chisquare on all of the sequence pairs. Chi-square analyses resulted in 182 behaviour pairs occurring above the level of chance. This is a limitation of focusing only on $p$ value statistical testing. Several authors have suggested that significance testing alone is not sufficient for sequence analysis, and suggest more stringent cut-off criteria (Keatley et al., 2017; Klonek, Quera, \& Kauffeld, 2015). Therefore, in order to make the number of significant transitions comprehensible, only those pairs of behaviours with high frequency and standardised residuals (SR) are shown in the current results ${ }^{4}$. Behaviour pairs occurring more than seven times were selected as a stringent criteria. The cut-off point of seven, meant a clear and comprehensible diagram was able to be produced, with complete start-to-finish chains being made.

\section{-Table 1 Here-}

Finally, a state transition diagram (See Figure 1) was developed to show pairs of behaviours that participants perceived to have taken place, from the start point of 'female leaves bar' to the end point of 'attacker rapes female'. Frequencies and standardised residuals (SR) are plotted alongside linking arrows in the diagram to provide indication of number and strength of difference between observed and expected values.

\subsection{Understanding the State Transition Diagram}

The diagram shows a start point of 'female leaves the bar' and an end point 'attacker rapes female'. Between the start and end point are pairs of behaviours that participants perceived to occur in an offence. The pairs linked together show a perceived chain of events from the start to the end. The state transition diagram shows points that appear to end

\footnotetext{
${ }^{4}$ Full transition matrices of all behaviours pairs are available from the correspondence author, on request.
} 
nowhere (e.g., female is looking down). It is important to note that all of the pairs of behaviours in the diagram were significant; however, as the cut-off point of frequency 7 was chosen, some routes stop before the 'end' point. For example, 'female listens to music' appears to end nowhere; however, this actually means the behaviours that were perceived to occur after that point, occurred less than 7 times. Breaks in the chain do not indicate the rape case ended at this point, it simply means this chain did not have a frequently occurring next transition point, on the criteria of 7 or more occasions. A cut-off of 7 was used as it provided the clearest diagram (i.e., without multiple complicated routes of lower frequency) that had pathways from start to finish. A cut-off of 6 would produce many more pathways, rendering the diagram harder to read and follow, whereas a cut-off of 8 lead to a break in the diagram midway. In this sense, the diagram is provided as a user-friendly account of the main results; whereas the full account of transitions can be seen in the Supplementary materials.

-Figure 1 here-

A further point to be clarified is regarding the connection between the start and end point on the state transition diagram. As a first-order sequence analysis was used, the state transition diagram indicates behavioural pairs. For example, 9 participants said a 'female leaves the bar' and 'looks up', and 7 participants suggested 'female looks up' is followed by 'female walks on main road'; however, 26 participants said a 'female leaves the bar' and directly 'walks on main road'. Each link in the state transition diagram shows only pairs of behaviours that occurred, as this is what the first-order sequence analysis demonstrates. It is not being suggested in the first-order sequence analysis that all 93 participants said the sequence started at 'female leaves the bar' and follows the exact same links through to 'attacker rapes female'. In short, the diagram should be interpreted as showing $\mathrm{A} \rightarrow \mathrm{B}, \mathrm{B} \rightarrow \mathrm{C}$ chains; though it is intuitively tempting, it would be wrong to assume from this that $\mathrm{A} \rightarrow \mathrm{B} \rightarrow \mathrm{C}$ occurs. 


\subsection{Analysis of the state transition diagram}

The first thing to notice is the dichotomy between the abundance of female or attacker actions. In the first (top) half of the diagram, the female is the main actor with multiple behaviours; however, once the attacker becomes part of the sequence, he performs most of the actions. Indeed, beyond verbal and physical threats, participants perceived a female’s only actions were to attempt to resist and scream. This perhaps indicates the change in control dynamics from beginning through to end.

The most frequently occurring behaviour pair sequences are as follows: 'attacker asks a question' to 'female responds to question' ( $\mathrm{SR}=30.0, n=36)$, 'attacker pulls female to ground' to 'attacker rips of female's clothes' ( $\mathrm{SR}=19.2, n=32)$, 'female screams' to 'attacker warns female not to scream' (SR = 21.0, $n=35)$, 'attacker warns female not to scream' to 'attacker covers females mouth' ( $\mathrm{SR}=20.4, n=34)$, and finally 'female is incapacitated' to 'attacker rapes female'(SR = 24.3, $n=37)$. Taking the first pairing of behaviours, i.e. 'attacker asks a question', what follows are two significant sequitur behaviours. One behaviour that follows is 'attacker asks for time' and the other is 'female responds to question'. The behavioural pairs with the highest frequency provided some results that make intuitive sense, for instance: ‘attacker asks a question' followed by 'female responds to question'.

It should also be noted that female participants in the current study thought an attacker would not randomly attack without prior conversational engagement with the female. There are no behaviour pairs that link directly from a female's actions to a male being violent. Participants perceived an attacker would ask a question after approaching the female or chat casually before threatening verbally (SR $=11, n=12$ ). Very few participants linked 'attacker approaching from behind' directly to the 'attacker threatens verbally' (SR = 5.4, $n=9)$. 
Finally, participants (SR $=18.8, n=22$ ) thought that verbal threats would precede physical threats.

\section{Discussion}

The main aim of this research was to provide a novel method to investigate females' perceptions of the interactions between a female victim and a male attacker, in a stranger rape case scenario. Sequence analysis provides an understanding of the patterns of behaviours in greater clarity and shows the progression of sequences of behaviours. In addition, examining perceived behavioural patterns can additionally highlight any misconceptions of rape; highlighting individuals’ false beliefs or rape myths (Kahn, Mathie, \& Torgler, 1994; Ryan, 2011; Ullman, 2007). More importantly, perception-based research may underpin mistaken ideas or beliefs females have about likely patterns of rape attacks.

The high frequency behaviour pair: 'female was incapacitated' to 'attacker rapes female' suggests participants perceived the female to be incapacitated in some way, immediately prior to the rape. The way in which individuals perceived the female to be incapacitated is unclear. It could imply the female is incapacitated due to a struggle with the attacker. However, an antecedent behaviour prior to the 'female is incapacitated' is 'attacker covers females mouth'. This could be what is meant by 'incapacitated', as the attacker has incapacitated the victim by covering her mouth. This finding overlaps with previous research, on real rape cases, that has shown the use of gagging to incapacitate a female's ability to scream or resist (Woodhams et al., 2008). Indeed, Woodhams and colleagues (2008) showed a number of different 'if-then’ contingencies between victim and offender behaviours, in real rape cases; several of these links were supported in the current research. For instance, female struggling and resisting lead to aggressive responses by the attacker in the current research (e.g., attacker pulls victim to the ground), which matches the high 
frequency if-then contingency of ‘victim struggles’ leading to ‘offender positions victim’ in Woodhams and colleagues' research. These findings also support the findings in Lawrence and colleagues' (2010) research on real rape cases, which showed sequences of an attacker responding aggressively to struggling or verbal resistance by the victim. Therefore, there is some evidence to suggest that participants' perceptions of rape cases matched real cases.

Research into rape myths and scripts has shown individuals typically think that rape will occur down a dark alleyway (Gölge et al., 2003). It seems that this is not the case in the current research. The most common perception in this research was that a 'female walks on a main road', which is the most frequent start of the pathway taken towards the final outcome. Indeed, females taking short-cuts or side-streets occur much less frequently. However, participants also suggested that the attacker would move the female to another location to then rape her. This could imply that the attacker moves the female to a 'dark alleyway' before committing the offence, which would support current rape myth views. Importantly, this could highlight that while the rape occurs in a dark alleyway, the preceding events leading up to this occur elsewhere.

There are limitations in the current research. The current research is based on females' perceptions of rape attacks, rather than police files. However, this is only a limitation of being able to generalise to actual attacks, not a limitation of the research itself, which highlights how perceptions can be investigated and misperceptions highlighted. A further limitation is that telling participants that the sequence ended with a rape attack means that a potential bias was given from the start, which may have affected selection of behaviours. Indeed, future research could also allow for alternative outcomes, with less constraint of bias of the type of behaviours included. Instead of having just one end point ('attacker rapes female'), an alternative end point, such as 'the female escapes' would provide an additional choice of perceived endings to choose from. This would show what sequence of behaviours females 
perceive to be the most likely to escape the situation, given different antecedent behaviours. Also, future research could investigate other areas of rape research, including male or acquaintance rape, as well as sexual assaults in different environments and contexts.

The current research still provides support for a novel method that can be used by future researchers and practitioners to understand perceptions of rape cases and crimes. Furthermore, the current research also shows a novel method for understanding females’ perceptions regarding rape, which could then be used as a tool for educational interventions. For example, as more research is conducted on this area, perceptions and misperceptions of most likely rape attack sequences could be shown to females, with the emphasis being on understanding how their scripts or perceived risk sequences do not match reality. The current method provides a very clear outcome, the state transition diagram, which can easily be understood by females to understand where their perceptions differ from others and from reality.

\section{Conclusions}

Overall, this research examined females’ perceptions of female and attacker interactions in stranger rape cases, using sequence analysis. This provides a clear sequence of events leading up to a rape attack. Results highlighted some support for previous research. Rape myths and scripts were also examined in relation to behaviour sequences shown in the current findings. Furthermore, rape myths may influence individuals' perception of what occurs during a rape, which is especially important when considering jury decision making; for instance, do some accounts seem more 'likely’ than others based on existing beliefs of behaviour sequences. Future research could develop the sequence analysis approach to clarify ambiguous behaviours, extend complexity of analyses, and incorporate a wider spectrum of possible behaviours. 


\section{References}

Ahlmeyer, S., Heil, P., McKee, B., \& English, K. (2000). The impact of polygraphy on admissions of victims and offenses in adult sexual offenders. Sexual abuse : a journal of research and treatment, 12(2), 123-138. doi:10.1177/107906320001200204

Alison, L. (2001). Unobtrusive measurement: using police information for forensic research. Qualitative Research, 1(2), 241-254. doi:10.1177/146879410100100208

Bakeman, R. \& Quera, V. (2011). Sequential analysis and observational methods for the behavioural sciences. Cambridge University Press.

Balemba, S. \& Beauregard, E. (2012). Where and when? Examining spatiotemporal aspects of sexual assault events. Journal of Sexual Aggression, 19, 171-190.

Canter, D. V., Benell, C., Alison, L. J., \& Reddy, S. (2003). Differentiating sex offences: A behaviourally based thematic classification of stranger rapes. Behavioural Sciences \& the Law,, 21(2), 157-174. doi:10.1002/bsl.526 .

Canter, D. \& Heritage, R. (1989). A multivariate model of sexual offense behaviour. Developments in offender profiling. Journal of Forensic Psychiatry, 1, 185-212.

Canter, D. \& Kirby, S. (1995). Prior convictions and child molesters. Science and Justice, 35, 73-78.

Carter, D. L., Prentky, A., \& Burgess, A. W. (1988). Victims: Lessons learned for responses to sexual violence. In R. K. Ressler, A. W. Burgess, \& J. E. Douglas (Eds.), Sexual homicide: Patterns and motives (pp. 105-132). Lexington, MA: Lexington Books

Da Silva, T., Woodhams, J., \& Harkins, L. (2014). Heterogeneity Within Multiple Perpetrator Rapes: A National Comparison of Lone, Duo and 3+ Perpetrator Rapes. Sexual 
Abuse: A Journal of Research and Treatment, 26(6), 503-522.

doi:10.1177/1079063213497805

Fossi, J. J., Clarke, D. D., \& Lawrence, C. (2005). Bedroom Rape: Sequences of Sexual Behaviour in Stranger Assaults. Journal of Interpersonal Violence, 20(11), 14441466. doi:10.1177/0886260505278716

Gölge, Z. B., Yavuz, M. F., Müderrisoglu, S., \& Yavuz, M. S. (2003). Turkish University Students' Attitudes Toward Rape. Sex Roles, 49(11/12), 653-661. doi:10.1023/b:sers.0000003135.30077.a4

Home Office and Ministry of Justice. (2013, January 10). An Overview of Sexual Offending in England and Wales. Retrieved January 22, 2016, from Gov.uk: https://www.gov.uk/government/statistics/an-overview-of-sexual-offending-inengland-and-wales

Ivanouw, J. (2007). Sequence analysis as a method for psychological research. Nordic Psychology, 59(3), 251-267. doi:10.1027/1901-2276.59.3.251

Jones, E. E. \& Gerard, H. B. (1967). Foundations of social psychology. New York: John Wiley.

Kahn, A. S., Mathie, V. A., \& Torgler, C. (1994). Rape scripts and rape acknowledgement. Psychology of Women Quarterly, 18, 53-66.

Kassing, L. R., \& Prieto, L. R. (2003). The Rape Myth and Blame-Based Beliefs of Counselors-in-Training Toward Male Victims of Rape. Journal of Counseling \& Development, 81(4), 455-461. doi:10.1002/j.1556-6678.2003.tb00272.x

Keatley, D. A., Barsky, A., \& Clarke, D. D. (2016). Drink driving in the UK: A sequence analysis approach. Psychology, Crime and Law. 
1 Kelly, L., Lovett, J., \& Regan, L. (2005). A gap or a chasm? Attrition in reported rape cases. London: London Home Office Research, Development and Statistics Directorate 2005.

Klonek, F. E., Quera, V., \& Kauffeld, S. (2015). Coding interactions in Motivational Interviewing with computer-software. Computers in Human Behaviour, 44(C), 284292

Koss, M. P., Figueredo, A. J., \& Prince, R. J. (2002). Cognitive mediation of rape's mental, physical and social health impact: Tests of four models in cross-sectional data. Journal of Consulting and Clinical Psychology, 70(4), 926-941. doi:10.1037/0022006X.70.4.926

Lawrence, C., Fossi, J., \& Clarke, D. (2010). A sequential examination of offenders' verbal stratergies during stranger rapes: the influence of location. Psychology, Crime \& Law, 16(5), 381-400. doi:10.1080/10683160902754964

Lees, S. (1997). Carnal knowledge: Rape on trial. London: Womens Press.

Levine-MacCombie, J., \& Koss, M. P. (1986). Acquaintance rape: Effective avoidance strategies. Psychology of Women Quarterly, 10(4), 311-319. doi:10.1111/j.14716402.1986.tb00756.x .

Lundrigan, S., \& Mueller-Johnson, K. (2013). Male Stranger Rape: A Behavioural Model of Victim-Offender Interaction. Criminal Justice and Behaviour, 40(7), 763-783. doi:10.1177/0093854812474451

Marono, A., Clarke, D. D., Navarro, J., \& Keatley, D. A. (2017a). A sequence analysis of nonverbal behaviour and deception. Journal of Police and Criminal Psychology. ISSN: 0882-0783 
1 Marono, A., Clarke, D. D., Navarro, J., \& Keatley, D. A. (2017b). A behaviour sequence analysis of nonverbal communication and deceit in different personality clusters. Psychiatry, Psychology, and Law. ISSN: 1321-8719

Office for National Statistics. (2015, April 23). Crime in England and Wales, year ending December 2014. Retrieved January 29, 2016, from http://www.ons.gov.uk/ons/dcp171778_401896.pdf

Page, A. D. (2008). Gateway to Reform? Policy Implications of Police Officers' Attitudes toward Rape. American Journal of Criminal Justice, 33(1), 44-58. doi:10.1007/s12103-007-9024-9

R Core Team. (2013). R: A language and environment for statistical computing. R Foundation for Statistical Computing, Vienne, Austria. ISBN 3-900051-07-0, URL http://www.R-project.org/.

Robertiello, G., \& Terry, K. J. (2007). Can we profile sex offenders? A review of sex offenders typologies. Aggression and Violent Behaviour, 12(5), 508-518. doi:10.1016/j.avb.2007.02.010.

Ryan, K. M. (2011). The relationship between rape myths and sexual scripts. The social construction of rape. Sex Roles, 65, 774-782.

Scully, D. (1990). Understanding sexual violence: A study of convicted rapists. London: HarperCollins Academic.

Sleath, E., \& Woodhams, J. (2014). Expectations about victim and offender behaviour during stranger rape. Psychology, Crime \& Law, 20(8), 798-820. doi:10.1080/1068316X.2013.876500 
1 Taylor, O., Keatley, D. A., \& Clarke, D. D. (2017). A behaviour sequence analysis of

2 perceptions of alcohol Journal of Interpersonal Violence. ISSN: 0886-2605

Taylor, P. J., Jacques, K., Giebels, E., Levine, M., Best, R., Winter, J., \& Rossi, G. (2008). Analysing forensic processes: Taking time into account. Issues in Forensic Psychology(8), 43-55. Retrieved from http://eprints.lancs.ac.uk/id/eprint/49932

Ullman, S. E. (2007). A 10-year update of "review and critique of empirical studies of rape avoidance". Criminal Justice and Behaviour, 34(3), 411-429. doi:10.1037/e674692007-001

Warner, R. M. (1992). Sequential analysis of social interaction: Assessing internal versus social determinants of behaviour. Journal of Personality and Social Psychology, 63(1), 51-60. doi:10.1037/0022-3514.63.1.51 .

Waterhouse, G. F., Reynolds, A., \& Egan, V. (2016). Myths and legends: the reality of rape offences reported to a UK police force. European Journal of Psychology Applied to Legal Context, 8, 1-10.

Woodhams, J., Hollin, C. R., Bull, R. (2008). Incorporating context in linking crimes: An exploratory study of situational similarity and if-then contingencies. Journal of Investigative Psychology and Offender Profiling, 5, 1-23.

Woodhams, J., Hollin, C. R., Bull, R., \& Cooke, C. (2012). Behaviour Displayed by Female Victims During Rapes Committed by Lone and Multiple Perpetrators. Psychology, Public, Policy and Law, 18(3), 415-452. doi:10.1037/a0026134. 